\title{
Costs of Formal and Informal Home Care and Quality of Life for Patients with Multiple Sclerosis in Sweden
}

\author{
Marianne Svensson ${ }^{1}$ and Liberty Fajutrao ${ }^{2}$ \\ ${ }^{1}$ The Swedish Institute for Health Economics, Box 2127, 22002 Lund, Sweden \\ ${ }^{2}$ Merck Serono Sweden, Merck AB, Box 3033, 16903 Solna, Sweden \\ Correspondence should be addressed to Liberty Fajutrao; liberty.fajutrao@merckgroup.com
}

Received 10 October 2013; Accepted 19 November 2013; Published 4 March 2014

Academic Editor: Angelo Ghezzi

Copyright (c) 2014 M. Svensson and L. Fajutrao. This is an open access article distributed under the Creative Commons Attribution License, which permits unrestricted use, distribution, and reproduction in any medium, provided the original work is properly cited.

\begin{abstract}
Disease progression in multiple sclerosis leads to dramatic changes in a person's ability to perform daily activities and increases reliance on external help. This study aims to describe and to estimate costs of formal/informal home care and quality of life related to multiple sclerosis. A mailed survey to a random sample of MS sufferers $(n=1500)$ collected data on the number of hours of home care received, type of help, productivity losses, quality of life, and disease characteristics. Costs for home care were estimated in $2012 €$ and factors that may influence the likelihood of getting home care were also evaluated. Formal care was given to $27 \%$ of the respondents $(n=839)$ at an average of $238.7 \mathrm{hrs} /$ month at a mean monthly cost of $€ 2873 /$ person with MS. Informal care was received by $49 \%$ of the respondents at an average of $47.3 \mathrm{hrs} / \mathrm{month}$ at a mean monthly cost of $€ 389 /$ person with MS. Utilities across disease severity are as follows: mild MS $=0.709(\mathrm{sd}=0.233)$, moderate $\mathrm{MS}=0.562(\mathrm{sd}=0.232)$, and severe $\mathrm{MS}=0.284(\mathrm{sd}=$ 0.283). Total home care costs increased with increasing disease severity. Informal caregiving contributes significantly to MS home care in Sweden.
\end{abstract}

\section{Introduction}

In Sweden, estimated 17,000 of the population are diagnosed with multiple sclerosis (MS) [1]. The reported prevalence of MS was $188.9 / 100,000$ of the population in 2008, with twice more women affected than men [2]. About a third of these individuals with MS are over 60 years old. About 5 persons in 100,000 are newly diagnosed with the disease each year.

MS is a chronic, highly variable, and unpredictable disease whose onset may be signaled by an attack of neurologic dysfunction such as blurred vision, extreme fatigue, pain, numbness in extremities, loss of movement, or speech problems (clinically isolated syndrome). This is typically followed by acute relapses in between periods of clinical remission (relapsing-remitting MS). When MS is left untreated, a progressive phase may ensue where there is gradual accumulation of disability with or without relapses (secondaryprogressive MS). In about $10 \%$ of the diagnosed individuals, neurologic function gradually deteriorates continuously with no occurrence of relapses (primary-progressive MS).
Disease progression is associated with functional disability including mobility problems, bladder dysfunction, pain, depression, and cognitive changes [3]. These impact the patient's ability to do day-to-day activities and increase the reliance on external help $[4,5]$. Diseased individuals and people around them need to adapt their lifestyle and/or their working and living environments to accommodate the changing needs of the MS patient. The impact of the disease is most felt by those diagnosed during the productive years when families and careers are developing $[6,7]$.

Although there is no cure for MS, several diseasemodifying therapies exist to reduce relapse rates, slow disability progression, and modify the overall disease course. Long-term therapy is needed, and adherence to therapy is a big challenge. Low adherence to treatment has been shown to lead to higher rates of relapses and progression with its associated increase in the utilization of health care resources [8].

MS results in a considerable economic burden to the Swedish society. Estimates in 2008 euros showed that 
TABLE 1: Unit costs.

\begin{tabular}{|c|c|c|c|}
\hline Cost item & Cost in SEK & Cost in euro & Source \\
\hline \multicolumn{4}{|l|}{ Community services } \\
\hline $\begin{array}{l}\text { Home help services } \\
\text { (per hour) }\end{array}$ & 439 & 50 & $\begin{array}{l}\text { Swedish Association of Local } \\
\text { Authorities and Regions (2011) }\end{array}$ \\
\hline $\begin{array}{l}\text { Personal assistant } \\
\text { (per hour) }\end{array}$ & 439 & 50 & $\begin{array}{l}\text { Swedish Association of Local } \\
\text { Authorities and Regions (2011) }\end{array}$ \\
\hline Informal care (per hour) & 146 & 18 & $\operatorname{SCB}(2012)^{1}$ \\
\hline $\begin{array}{l}\text { Caregivers production losses } \\
\text { (per hour) }\end{array}$ & 271 & 31 & $\operatorname{SCB}(2012)^{1 ; 2}$ \\
\hline $\begin{array}{l}\text { Caregivers sick leave } \\
\text { (per day) }\end{array}$ & 1092 & 125 & $\operatorname{SCB}(2012)^{1 ; 3}$ \\
\hline
\end{tabular}

${ }^{1}$ Statistics Sweden (2012) Gross Wages year 2011 (http://www.scb.se/Pages/TableAndChart_-__149087.aspx).

${ }^{2}$ Assumption: 229 work days per year (full-time) and eight hours per day.

${ }^{3}$ Assumption: full-time wages adjusted for $80 \%$ of the employment. Number of sick days was specified in the questionnaire for periods of weeks, where annual earnings were allocated to 365 days.

the total annual costs of MS according to disease severity were the following: EDSS $<4 € 27,570$, EDSS 4-6.5 $€ 45,769$, and EDSS > $6.5 € 104,492$ with an average total cost per patient amounting to $€ 46,289$ [9]. Direct nonmedical costs, that is, formal help in home, transportation, aids, devices, and adaptations, accounted for $30 \%$ and informal care accounted for $10 \%$ of the total cost per patient $[6,9]$.

\section{Objectives}

The objectives of this study are to describe and to estimate the costs of formal and informal home care related to MS and the quality of life of the study population.

\section{Methods}

3.1. Study Design. A random sample of 1500 members of the Swedish Organization for Patients with Neurological Diseases (Neuroförbundet), specifically those with MS, were mailed a letter with study information and study consent to participate along with the study questionnaire between February and March 2012. The recall period was one month up to the time of the survey. Completed questionnaires containing no patient identification data were then sent back for further analyses. Reminders were sent to all after two weeks.

3.2. Data Collection. Respondents were asked to indicate their use of formal and/or informal home caregivers at the time of the study using questions with yes/no answers followed by specification of the type and quantity of the resources used. Instructions to include only MS-related care were given. Formal care data were reported as the number of hours per month that care was performed by publicly funded home help services and/or personal assistance. Informal care data were reported as the number of hours per month that family, relatives, and/or friends help with personal care (bathing, dressing, and moving indoors/outdoors), services (cleaning, washing, and shopping), and transport (travel to/from work and medical visits).
Production losses due to informal caregiving were reported as sick leave days during the last year as well as changes in working hours to accommodate caregiving tasks.

EQ-5D-3L was incorporated in the questionnaire as a measure of health-related quality of life. Respondent characteristics including gender, age, educational level, living situation, and drug treatment received were collected. Disease information included self-reported information on year of MS diagnosis, type of MS, and self-assessed current EDSS level. The Expanded Disability Status Scale (EDSS) measures an individual's functional capacity. In this study, a selfassessed version developed for use in a mail survey was utilized [6].

3.3. Costs. Unit costs of formal care were taken from a 2011 report of the Swedish Association of Local Authorities and Regions, where estimates for home help services were calculated and allocated per elderly in 2010. One hour of formal home help services included personnel time in a person's home, travel time, and time for the administration of any treatment. The same unit costs were used for one hour of personal assistance.

Informal care was valued by the opportunity cost approach arguing that time spent on caring cannot be used for other activities such as paid work and/or leisure activities. An hour of informal care was valued by an individual's income loss based on the mean salary (adjusted by average work time) in the general population for 2011 after $32 \%$ tax. The production losses of caregivers due to sick leave or changed working hours were valued using paid average wages including the employers' costs of benefit package of $42 \%$. All costs were presented in euros at 2012 prices after adjustments using the consumer price index. Unit costs are presented in Swedish kronor (SEK) and euros, using the annual average 2012 exchange rate of $1 €=8.7053$ SEK (Table 1 ) [10].

3.4. Analysis. Prior to analysis, invalid and inconsistent entries were identified and labeled as missing. To derive the total costs of formal and informal home care, resource utilization data were multiplied by their unit costs and 
estimated as the mean cost per person with MS. It was assumed that the reported resource utilization during the study represented a typical monthly level of resource use of an individual. The estimation of informal health care costs included the actual hours per month given by informal care, the number of days per year reported as sick leave in order to care for the affected family member, and the reported changes in employment (e.g., decrease in time for paid work) in order to care for the sick. Since costs of care are oftentimes dependent on disease severity, the results were analyzed and reported by EDSS level. EDSS scores were categorized into three severity groups: mild (EDSS 0-3), moderate (EDSS 46 ), and severe (EDSS $\geq 6.5$ ) [11].

Factors that may affect the likelihood that an individual with MS will get home care were also evaluated. A semilogarithmic linear regression analysis using STATA was performed with the following independent variables: age, gender, housing condition, number of years diagnosed with MS, and disease severity. EQ-5D-3L was not included in the regression analysis because of a high correlation with EDSS.

EQ-5D-3L utilities were estimated using UK tariffs [12].

\section{Results}

4.1. Patient Demographics. A total of 839 questionnaires were received (56\% response rate) of which $77 \%$ of the responders were female. Of the returned questionnaires, 7 respondents explicitly refused participation to the survey. One of the respondents was excluded from the analysis because he/she was under institutional care during the survey. The mean age of the sample was 56 years $(\mathrm{sd}=11.8)$ with $27 \%$ of the respondents having 65 years or more. The mean number of years since the diagnosis of MS was 17 years $(s d=11.3)$ with $39 \%$ of the respondents reporting having primary progressive MS and 26\% with secondary progressive MS. Around 39\% had severe disease (EDSS $\geq 6.5$ ) and $28 \%$ reported having mild disease (EDSS 0-3). The majority of the respondents were living with someone (69\%) and $41 \%$ attained a high level of education (Table 2).

4.2. Formal and Informal Care. Table 3 summarizes the proportions of respondents receiving formal home care and informal care, as well as intensity of services received. In this sample, over a quarter of the respondents $(27 \%)$ reported receiving formal care at home, $14 \%$ received municipal home help services, and $17 \%$ received personal assistance services. Both forms of community services were received by $17 \%$ of the respondents $(n=225)$. A respondent receives an average of 239 hours per month of formal home care. The mean number of hours of formal care is highest for respondents with severe disease ( 267 hours/month).

Almost half of the respondents (49\%) reported being helped at home by family and friends. Help was most needed with daily activities/services (29\%), followed by personal care (13\%) and transport (5\%). The average number of hours of informal home care was 47 hours per month. Respondents with severe MS needed more help (70 hours) than those with
TABLE 2: Sample demographics.

\begin{tabular}{|c|c|c|}
\hline & Number & Percent \\
\hline Total number of responders & 831 & \\
\hline \multicolumn{3}{|l|}{ Gender } \\
\hline Female & 637 & $77 \%$ \\
\hline Male & 189 & $23 \%$ \\
\hline Missing & 5 & $1 \%$ \\
\hline \multicolumn{3}{|l|}{ Age } \\
\hline $18-34$ years & 34 & $4 \%$ \\
\hline $35-44$ years & 100 & $12 \%$ \\
\hline $45-54$ years & 215 & $26 \%$ \\
\hline $55-64$ years & 247 & $30 \%$ \\
\hline 65-years & 227 & $27 \%$ \\
\hline Missing & 8 & $1 \%$ \\
\hline \multicolumn{3}{|l|}{ Education } \\
\hline Primary school & 165 & $20 \%$ \\
\hline High school degree & 319 & $38 \%$ \\
\hline Professional diploma/university degree & 340 & $41 \%$ \\
\hline Missing & 7 & $1 \%$ \\
\hline \multicolumn{3}{|l|}{ Household } \\
\hline Single & 256 & $31 \%$ \\
\hline Cohabiting & 575 & $69 \%$ \\
\hline \multicolumn{3}{|l|}{ Type of MS } \\
\hline Relapsing-remitting & 204 & $24 \%$ \\
\hline Secondary progressive & 220 & $26 \%$ \\
\hline Primary progressive MS & 321 & $39 \%$ \\
\hline Do not know & 76 & $9 \%$ \\
\hline Missing & 10 & $1 \%$ \\
\hline \multicolumn{3}{|l|}{ Using pharmaceutical } \\
\hline Yes, injection & 204 & $24 \%$ \\
\hline Yes, infusion & 83 & $10 \%$ \\
\hline Yes, oral & 109 & $13 \%$ \\
\hline Yes, combination therapy & 12 & $1 \%$ \\
\hline No & 417 & $50 \%$ \\
\hline Missing & 6 & $1 \%$ \\
\hline \multicolumn{3}{|l|}{ Disease severity } \\
\hline Mild (EDSS 0-3) & 236 & $28 \%$ \\
\hline Moderate (EDSS 4-6) & 244 & $29 \%$ \\
\hline Severe (EDSS $\geq 6.5$ ) & 321 & $39 \%$ \\
\hline Missing & 30 & $4 \%$ \\
\hline
\end{tabular}

less severe MS. It was also reported that $81 \%$ of informal caregivers were cohabitants of the person with MS.

Changes in working hours by informal caregivers as a result of caregiving tasks were reported by $3 \%$ of the respondents (Table 3 ). On average, working time decreased to 16 hours/week $(s d=10.8)$. Informal caregivers took an average of 8.4 days per year as sick leave days in order to care of the person with MS, as reported by $5 \%$ of the respondents.

Across the sample, the mean total number of hours of home care per month was 78.3 hours per person $(s d=6.2)$, of which informal care accounted for 21.3 hours $(s d=1.7$ ). Monthly production losses due to informal care (i.e., sick 
TABLE 3: Formal and informal care per home care user.

\begin{tabular}{|c|c|c|c|}
\hline & \multirow{2}{*}{$\begin{array}{l}\text { Proportion with help } \\
\%\end{array}$} & \multicolumn{2}{|c|}{ Quantity per home care user during recall period } \\
\hline & & Mean & $95 \% \mathrm{CI}$ \\
\hline Formal care & \multicolumn{3}{|c|}{ Hours per month } \\
\hline $\begin{array}{l}\text { (Home help services and/or personal } \\
\text { assistance) }\end{array}$ & $27 \%$ & 238.7 & $203.9-243.5$ \\
\hline \multicolumn{4}{|l|}{ By disease severity } \\
\hline Mild (EDSS 0-3) & $1 \%$ & 4 & - \\
\hline Moderate (EDSS 4-6) & $9 \%$ & 38 & $-6.0-82.0$ \\
\hline Severe (EDSS $\geq 6.5$ ) & $60 \%$ & 267 & $228.4-304.8$ \\
\hline Informal care & $49 \%$ & 47.3 & \\
\hline \multicolumn{4}{|l|}{ Type } \\
\hline Service & & 29.0 & \\
\hline Personal care & & 12.9 & \\
\hline Transport & & 5.4 & \\
\hline \multicolumn{4}{|l|}{ By disease severity } \\
\hline Mild (EDSS 0-3) & $19 \%$ & 14 & $11.5-17.6$ \\
\hline Moderate (EDSS 4-6) & $55 \%$ & 27 & $22.2-31.9$ \\
\hline \multirow[t]{2}{*}{ Severe (EDSS $\geq 6.5$ ) } & $68 \%$ & 70 & $57.1-83.3$ \\
\hline & \multicolumn{3}{|c|}{ Days per year } \\
\hline \multirow[t]{2}{*}{ Caregivers sick leave } & $5 \%$ & 8.4 & $6.3-10.6$ \\
\hline & \multicolumn{3}{|c|}{ Hours per week } \\
\hline Caregivers changed working hours & $3 \%$ & 15.8 & $11.6-20.0$ \\
\hline
\end{tabular}

leave and modifications in working hours) were estimated to be about 2.2 hours per person $(\mathrm{sd}=0.5)$ (data not shown).

4.3. Utility. The EQ-5D was completed by $88 \%$ of the respondents. The average estimated utility of the sample was estimated at $0.513(\mathrm{sd}=0.307)$. Across disease severity, utility was estimated as follows: mild $\mathrm{MS}=0.709(\mathrm{sd}=0.233)$, moderate $\mathrm{MS}=0.562(\mathrm{sd}=0.232)$, and severe $\mathrm{MS}=0.284(\mathrm{sd}$ $=0.283)$. The health utility scores correlated with the EDSS scores (Kruskal-Wallis $P<0,01$ ).

4.4. Costs. The estimated monthly costs for formal and informal care per home care user as well as the mean monthly costs per person with MS in the sample are shown in Table 4. The estimated total monthly home care costs per person are $€ 3262$ of which $€ 2873$ (88\%) accounted for formal care costs and $€ 389$ for informal care costs. Monthly production losses due to sick leave and/or lower productivity of caregivers accounted for $18 \%$ ( $€ 69$ per person) of the informal care costs. For respondents with severe MS, the estimated total monthly home care costs amounted to $€ 8446,90 \%$ of which is spent on formal care and $10 \%$ on informal care.

Table 5 shows the results of the regression analyses of factors influencing total costs of home care and their categories, that is, formal and informal costs. The reported coefficients reflect the percent change in costs, if the independent variable changes by one unit. Total monthly home care costs are significantly higher for those aged 35-44 years old, those with moderate-severe MS, and those who are cohabiting with someone and are higher as the number of years since the diagnosis of MS increases (all other variables are equal). Men have relatively lower total costs than women $(-63 \%)$. Respondents in the working age category (35-44 yrs) have twice the total costs of respondents aged 18-34 years. Those with moderate and severe disease have a 3 -fold and almost 8 -fold increase in the total costs compared to those with mild disease. Respondents cohabiting with someone have $70 \%$ higher costs than those living alone.

For formal care costs, factors leading to higher costs include severe MS and higher number of years since diagnosis. To live with someone lowers formal care costs by around $157 \%$ compared to those living alone (all other variables are equal). Informal care costs are shown to be higher for those between 35 and 44 years old (141\% higher), for those with moderate MS (300\% increase) and, for those with severe MS ( $500 \%$ increase) as well as for those cohabiting with someone (350\% increase) compared to those who are younger, those with mild disease, and those who live alone, respectively.

\section{Discussion}

This mail survey aimed to describe and to estimate the costs associated with formal and informal home care for a random sample of members with MS of the Neuroförbundet, an organization of patients with neurological diseases in Sweden. The sample population consisted of $77 \%$ females with a mean age of 56 years and almost $70 \%$ of whom were 
TABLE 4: Estimated monthly costs for formal and informal care per home care user and per person with MS in the sample (euro, 2012 prices).

\begin{tabular}{|c|c|c|c|c|c|c|}
\hline \multirow{2}{*}{ Formal care } & \multicolumn{3}{|c|}{ Monthly cost per home care user* } & \multicolumn{3}{|c|}{ Monthly cost per person with MS** $(n=740)$} \\
\hline & Mean & \multicolumn{2}{|c|}{$95 \% \mathrm{CI}$} & Mean & \multicolumn{2}{|c|}{$95 \% \mathrm{CI}$} \\
\hline (Home help services and/or personal assistant) & 12037 & 10282 & 13791 & 2873 & 2299 & 3448 \\
\hline \multicolumn{7}{|l|}{ By disease severity } \\
\hline Mild (EDSS 0-3) & 202 & 0 & 0 & 1 & -1 & 3 \\
\hline Moderate (EDSS 4-6) & 1918 & -300 & 4137 & 184 & -36 & 403 \\
\hline Severe $($ EDSS $\geq 6.5)$ & 13443 & 11516 & 15369 & 7641 & 6227 & 9055 \\
\hline Informal care & 893 & 759 & 1026 & 389 & 327 & 451 \\
\hline \multicolumn{7}{|l|}{ By disease severity } \\
\hline Mild (EDSS 0-3) & 345 & 213 & 478 & 62 & 33 & 91 \\
\hline Moderate (EDSS 4-6) & 527 & 412 & 643 & 278 & 208 & 347 \\
\hline Severe (EDSS $\geq 6.5$ ) & 1302 & 1066 & 1538 & 805 & 653 & 957 \\
\hline Total home care & 5640 & 4688 & 6593 & 3262 & 2677 & 3848 \\
\hline \multicolumn{7}{|l|}{ By disease severity } \\
\hline Mild (EDSS 0-3) & 342 & 66 & 212 & 63 & 0 & 0 \\
\hline Moderate (EDSS 4-6) & 791 & 408 & 1174 & 461 & 34 & 92 \\
\hline Severe (EDSS $\geq 6.5$ ) & 9204 & 7696 & 10712 & 8446 & 233 & 689 \\
\hline
\end{tabular}

*Estimated for those who availed of formal and/or informal care in sample.

${ }^{* *}$ Estimated for all respondents in the sample, whether had home care or not.

TABLE 5: Results of regression analyses for total home care costs, formal care costs, and informal care costs for persons with MS in Sweden.

\begin{tabular}{|c|c|c|c|}
\hline \multirow{2}{*}{ Independent variable } & Total home care costs $(n=699)$ & Formal care costs $(n=747)$ & Informal care costs $(n=718)$ \\
\hline & Coefficient & Coefficient & Coefficient \\
\hline \multicolumn{4}{|l|}{ Gender } \\
\hline \multicolumn{4}{|l|}{ Female $^{\dagger}$} \\
\hline Male & $-0.629^{*}$ & 0.316 & -0.497 \\
\hline \multicolumn{4}{|l|}{ Age in years } \\
\hline \multicolumn{4}{|l|}{$18-34^{\dagger}$} \\
\hline $35-44$ & $1.824^{*}$ & 0.330 & $1.412^{*}$ \\
\hline $45-54$ & 0.508 & -0.475 & 0.227 \\
\hline $55-64$ & 0.637 & -0.883 & 0.577 \\
\hline $65+$ & 0.408 & -1.040 & 0.327 \\
\hline \multicolumn{4}{|l|}{ Disease severity } \\
\hline \multicolumn{4}{|l|}{ Mild (EDSS 1-3) ${ }^{\dagger}$} \\
\hline Moderate (EDSS 4-5) & $3.300^{*}$ & 0.596 & $2.970^{*}$ \\
\hline Severe (EDSS $\geq 6.5$ ) & $7.693^{*}$ & $5.395^{*}$ & $4.842^{*}$ \\
\hline \multicolumn{4}{|l|}{ Living arrangement } \\
\hline \multicolumn{4}{|l|}{ Living alone $e^{\dagger}$} \\
\hline Cohabiting & $0.693^{*}$ & $-1.572^{*}$ & $3.512^{*}$ \\
\hline Years since MS diagnosis & $0.056^{*}$ & $0.091^{*}$ & -0.002 \\
\hline Constant & -0.455 & 0.511 & $-1.703^{*}$ \\
\hline$R^{2}$ & $49.66 \%$ & $43.41 \%$ & $33.52 \%$ \\
\hline
\end{tabular}

cohabiting. Around $40 \%$ of the respondents had primary progressive MS, $24 \%$ had relapsing remitting MS, and $26 \%$ had secondary progressive MS. Mild, moderate, and severe diseases were reported in approximately 30\%, 30\%, and $40 \%$ of the sample, respectively. It was not possible to determine the representativeness of this sample to the Swedish MS population because of the unavailability of data.

In this sample, respondents with severe disease (EDSS $\geq 6.5$ ) were highly likely to require formal care in terms of home help services and/or personal assistance as 
well as informal care from family or friends. It is estimated that those with severe MS require 267 hours of formal care per month and 70 hours of informal care per month on the average, amounting to about $€ 8446$ per person-month. For those with mild disease (EDSS 0-3), informal care is the most resorted to, requiring only an average of 4 hours of formal care and 14 hours of informal care per month, or $€ 63$ per person-month.

In 2006, a major European study on the costs and quality of life of people with MS in nine countries including Sweden using a similar methodology as this study was published [6]. Compared to the 2006 Swedish sample, this present study had more individuals with primary progressive MS and who are aged 65 years and above. The reported utilities as measured by EQ-5D were also slightly lower in our study. Although there are differences in the characteristics of the respondents between the two studies, it is notable that the present study reported the same proportion of formal home care services users.

A comparison of the results shows that the number of hours of home help services per month is lesser in our study, 49 hours per user-month versus 27 hours per user-month, respectively. Although the proportions of respondents who required personal assistance are similar in both studies, the present study reports about 70 hours more per user-month. This finding suggests a shift from home help services to personal assistance between the years 2005 and 2012 when the studies were conducted (data not shown).

The proportion of respondents receiving informal care is lower in our study (57\% versus $49 \%$ ). Information on how informal care is provided is not available in the Berg study. On average, the reported number of hours for informal caregiving is also lower in our study. This might probably be due to differences in how the questions were worded. In the Berg study, it asked the respondents about the number of hours they had assistance from family and friends over the past month. In our study, the respondent was asked to specify the number of hours they received help with services, personal care, and transport from family or friends. It is highly probable that the Berg study included the number of hours that the family member was present in the home whether or not any service was actually done. Our study showed the complementary nature of informal care to formal care, whereby if no family or friend can give help, then help is provided by formal care services.

The total costs of home care are very much dependent on disease severity, length of MS diagnosis, and living arrangements. Costs of formal care increase with disease severity, whether number of years diagnosed with MS, and the the respondent is living alone. Costs of informal care also increase with the severity of the disease and whether the respondent is cohabiting or not. Compared to respondents with mild MS, those with moderate MS have threefold the cost of mild MS and those with severe MS have a sevenfold increase in the total costs of home care (all other variables are equal).

Production losses attributable to sick leave or decrease in employment amount to $18 \%$ of informal care costs. We believe that this is the first time that productivity losses of caregivers of people with MS in Sweden are reported. Due to the overrepresentation of patients with moderate and severe disease, even possibly patients with progressive course of disease, it is not directly possible to extrapolate costs to the overall MS population in Sweden, nor can the study sample be considered representative of the general MS population.

This study can be considered as describing a sample of persons diagnosed with MS belonging to a specific patient organization. Some adjustments were made to make sure that the number of persons within different severity-of-disease categories will be similar for estimation of costs so the sample may not be a valid cross-section of the distribution of MS patients in Sweden. Nonresponse to the mailed survey is estimated at $44 \%$ which could have affected the study results. Resource use data was collected using a recall period of one month. It is believed that heterogeneity exists in the number, personal characteristics, availability, and qualifications of the caregivers which could have some impact on the efficiency of how care is given.

\section{Conclusion}

Formal care costs accounted for a large proportion of total home care costs despite the fact that a greater proportion of MS patients received informal home care in this study sample. Total home care costs increased with increasing disease severity. Patients cohabiting with an informal caregiver had lower formal care costs but higher informal costs. Family members or informal caregivers save the health care system from additional formal care costs but increase the total costs of care to society because of the caregivers' decreases in productivity or sick-leaves. This highlights the contribution of informal caregiving to the overall home care of MS patients in Sweden thus providing the potential of cost-savings for the health care delivery system. Further research into the relationship between formal and informal home caregiving is necessary to help guide health resource allocation for the care of MS patients in Sweden.

\section{Conflict of Interests}

The authors declare that there is no conflict of interests regarding the publication of this paper. Liberty Fajutrao is an employee of Merck Serono Sweden.

\section{Acknowledgment}

The authors would like to acknowledge and thank the invaluable advice and generous support provided by Neuroförbundet in facilitating the survey.

\section{References}

[1] Svenska MS-registret, 2013, http://www.msreg.net.

[2] C. Ahlgren, A. Odén, and J. Lycke, "High nationwide prevalence of multiple sclerosis in Sweden," Multiple Sclerosis, vol. 17, no. 8, pp. 901-908, 2011. 
[3] R. J. Buchanan, D. Radin, and C. Huang, "Burden among male caregivers assisting people with multiple sclerosis," Gender Medicine, vol. 7, no. 6, pp. 637-646, 2010.

[4] S. Gupta, A. Goren, A. Phillips, and M. Stewart, "Self-reported burden among caregivers of patients with multiple sclerosis," International Journal of MS Care, vol. 14, pp. 179-187, 2012.

[5] U. Einarsson, K. Gottberg, S. Fredrikson, L. von Koch, and L. W. Holmqvist, "Activities of daily living and social activities in people with multiple sclerosis in Stockholm County," Clinical Rehabilitation, vol. 20, no. 6, pp. 543-551, 2006.

[6] J. Berg, P. Lindgren, S. Fredrikson, and G. Kobelt, "Costs and quality of life of multiple sclerosis in Sweden," European Journal of Health Economics, vol. 7, no. 2, pp. S75-S85, 2006.

[7] M. Gudesblatt, R. Goldstein, J. Kalina et al., "Multiple sclerosis: employment and employability-patient-reported perspectives," in Proceedings of the 28th Congress of the European Committee for Treatment and Research in Multiple Sclerosis (ECTRIMS '12), Lyon, France, October 2012.

[8] J. Menzin, C. Caon, C. Nichols, L. A. White, M. Friedman, and M. W. Pill, "Narrative review of the literature on adherence to disease-modifying therapies among patients with multiple sclerosis," Journal of Managed Care Pharmacy, vol. 19, supplement 1, pp. S24-S41, 2013.

[9] G. Kobelt, "Access to innovative treatments in multiple sclerosis in Europe," A Report Prepared for the European Federation of Pharmaceutical Industry Associations (EFPIA), 2009.

[10] Statistics Sweden, “Gross wages year 2011," 2012, http://www.scb .se.

[11] F. Henriksson, S. Fredrikson, T. Masterman, and B. Jönsson, "Costs, quality of life and disease severity in multiple sclerosis: a cross-sectional study in Sweden," European Journal of Neurology, vol. 8, no. 1, pp. 27-35, 2001.

[12] P. Dolan, "Modeling valuations for EuroQol health states," Medical Care, vol. 35, no. 11, pp. 1095-1108, 1997. 


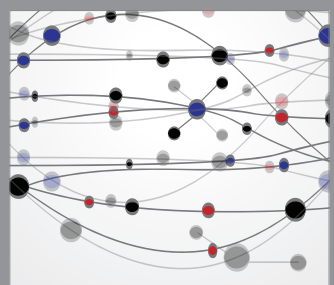

The Scientific World Journal
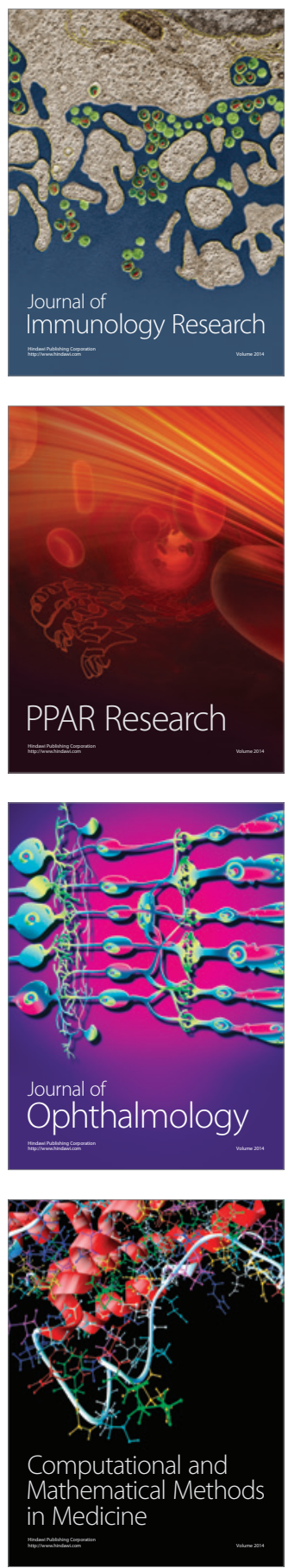

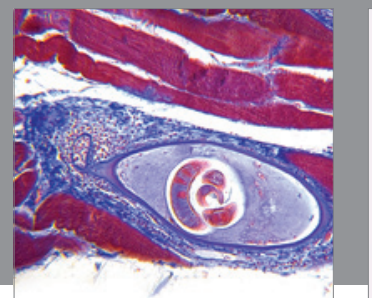

Gastroenterology

Research and Practice
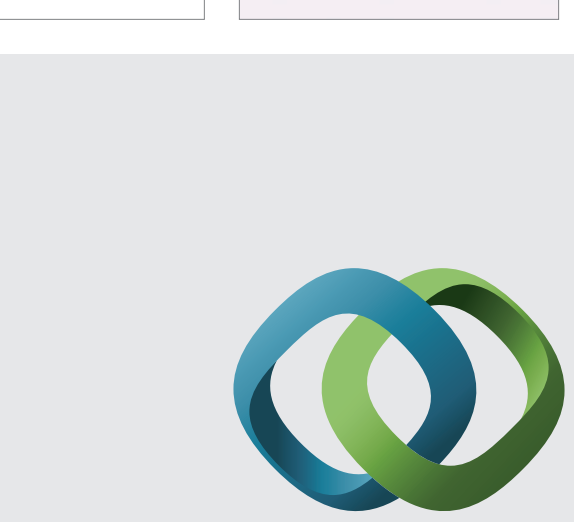

\section{Hindawi}

Submit your manuscripts at

http://www.hindawi.com
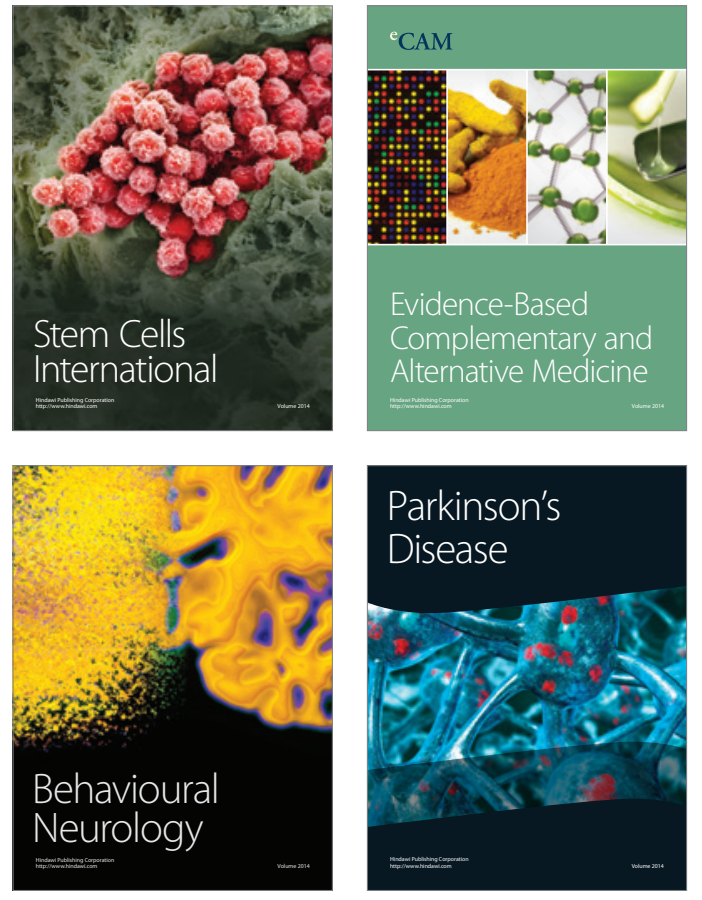
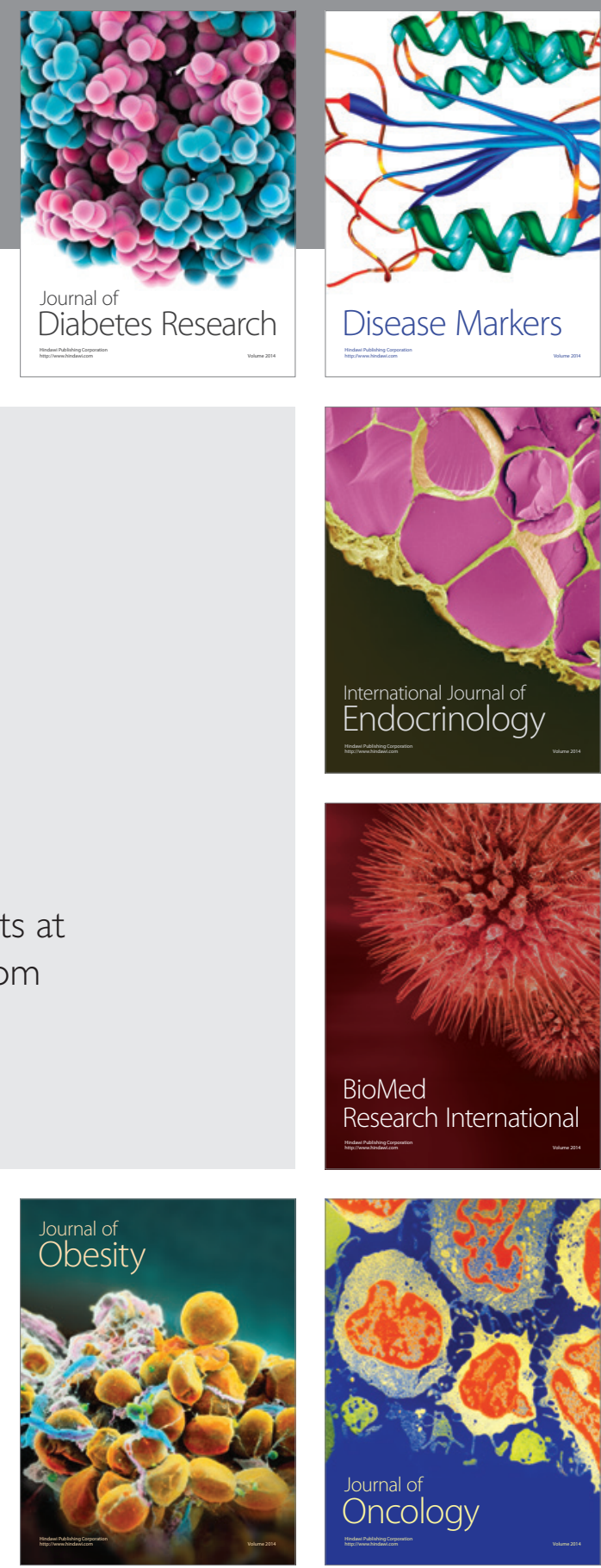

Disease Markers
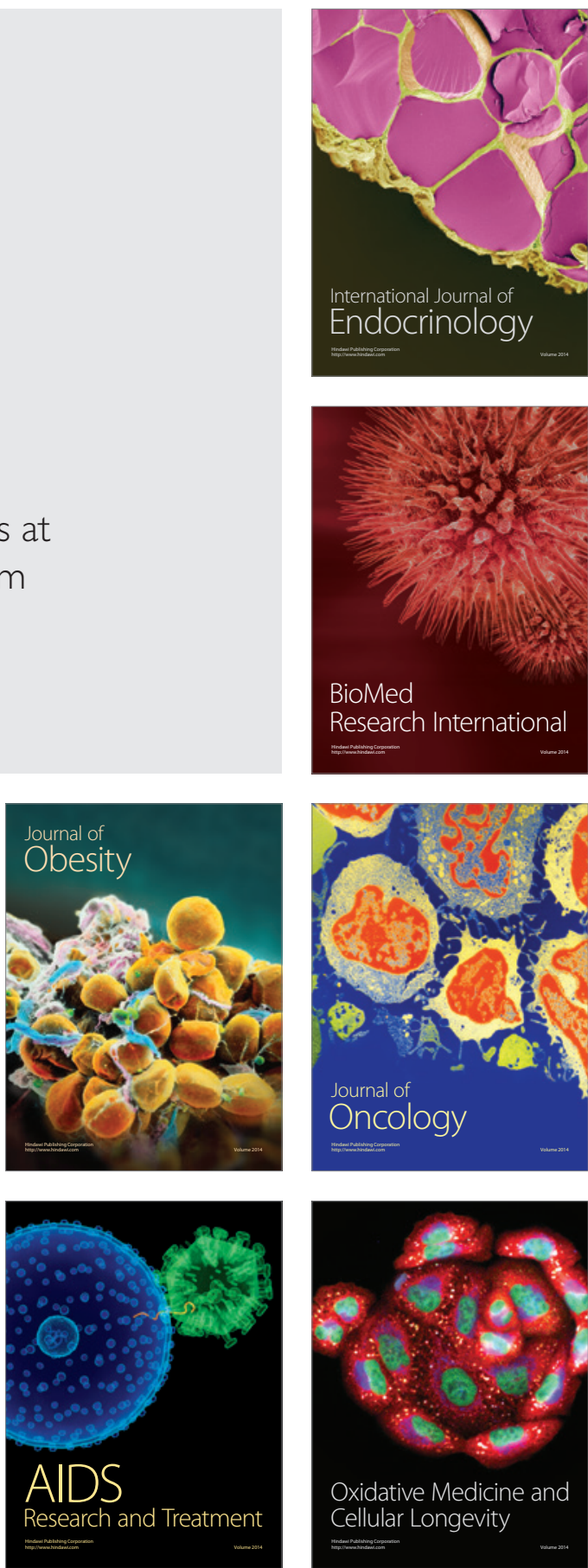